\title{
Forming teams: an analytical approach
}

\author{
ARMEN ZAKARIAN and ANDREW KUSIAK \\ Intelligent Systems Laboratory, Department of Industrial Engineering, The University of Iowa, Iowa City, IA 52242-1527, USA
}

Received September 1997 and accepted February 1998

\begin{abstract}
The selection of multi-functional teams is a key issue in problem solving. Currently there are no papers in the literature that discuss analytical approaches to forming teams. Furthermore, no comprehensive model exists to prioritize team membership based on customer requirements or product characteristics. To deal with the underlying complexities of the team selection process, a methodology for team formation is developed. The methodology is based on the Analytical Hierarchy Process (AHP) approach and the Quality Function Deployment (QFD) method. A QFD planning matrix is used to organize the factors considered in the team selection. The importance measure for each team member is determined with the AHP approach. A mathematical programming model is developed to determine the composition of a team. The methodology developed in this paper is tested by the selection of teams in concurrent engineering. A detailed discussion of the model implementation and how to reduce the number of comparisons in the AHP process is presented. Possible modifications of the model to include "soft factors", i.e., leadership, morale, personalities of group members, group values and so on are also discussed.
\end{abstract}

\section{Introduction}

The concept of forming multi-functional teams has gained increasing attention in recent years. One of the most meaningful engineering efforts that has been built around a team concept is Concurrent Engineering (CE). $\mathrm{CE}$ involves making complex decisions in product design so that downstream issues such as manufacturability, serviceability, marketability, and total life cycle problems, are anticipated in early steps [1]. The teamwork needed to meet these deliverables is the key ingredient of CE. Multi-functional teams facilitate continuous transmittal of information concerning the evolving product and manufacturing process, improve the outcome of a design process and create a product that satisfies customer and market requirements. CE success also requires supporting changes in the organizational environment surrounding a team, such as, transfer decision-making authority from managers to teams and redesign organizational reward systems to encourage the teamwork. For a more detailed description of the CE methodology see, for example, Carter and Baker [2].

Teams are defined as "a distinguishable set of two or more people who interact, dynamically, independently, and adaptively toward a common and valued goal/objective/mission, who have each been assigned specific roles or functions to perform, and who have limited lifespan of membership" [3]. In CE experts from various disciplines, such as, design, manufacturing, quality testing, and marketing, work in groups (teams) rather than individually in order to develop a quality product. The membership of a team depends on the type of product to be developed, customer requirements, engineering and product characteristics, and so on. The team approach has been used, for example, by the Ford Motor Company in the development of the Ford Taurus [4].

In spite of the importance of multi-functional teams in $\mathrm{CE}$, the literature does not provide analytical solutions for team formation. Furthermore, no comprehensive model exists to prioritize team membership based on the customer requirements or product characteristics. For example, when a multi-functional team is selected, it is not known how important is the information provided by a team member for a particular characteristic of the product or customer requirement. Lawrence and Lorsch [5] have indicated some of the basic conditions for the use of multi-functional teams in product development and have also provided the necessary structural characteristics for these teams. Askin and Sodhi [6] have presented an approach to organizing teams in CE. They have developed five different criteria for team formation and discussed team training, leadership, and computer support issues. The labor assignment heuristic was developed for team formation. The deficiency of the heuristic approach presented by Askin and Sodhi [6] is that it considers a single criterion, i.e., time, for forming teams. Also, it does not consider customer requirements and product characteristics. Reddy et al. [7] have proposed the notion of virtual teams to overcome the barriers of hierarchical organizational structures. In a virtual team geographically scattered team members use a computer-supported environment to collaborate over a network. A layered 
architecture of different types of computer technology has been described, i.e., network layer, enterprise information model layer, collaboration services layer, transformation layer, and activity layer, the integration of which enable a virtual team. Klein [8] has presented a Design Rationale Capture System (DRCS) for capturing design rationale in CE teams. The DRCS system integrates design-decisions and design-rationale in a single tool and allows more effective support for multi-functional design teams. Neither of these two papers $[7,8]$ offers a methodology for forming teams.

Considerable research effort has been devoted to empirical studies of team performance, the role of mental models in team performance, and capturing human skills and knowledge. Levine and Moreland [9] have summarized the progress of research on small group performance and they have concluded that group performance depends, at least in part, on the abilities and personalities of group members and the size and cohesiveness of the group. Armstrong [10] has compared the impacts of hierarchical and heterarchical organizational structures on the performance of three-person teams by using a manufacturing simulation. He concluded that teams in the hierarchy generally worked faster, while teams in the heterarchy worked with greater precision. He also found that heterachically organized team members were more focused on individual positions and often ignored system level information. Hauptman and Hirji [11] have performed an empirical study of cross-functional teams in $\mathrm{CE}$ and presented several insights useful for team performance. They found that the behavior and attitude of $\mathrm{CE}$ team members toward ambiguous and uncertain information had a considerable impact on CE project outcomes. The study also found a positive relationship between team member interdependence and team performance.

Both Kleinman et al. [12] and Luh et al. [13] have applied an optimization approach to model team performance. They used stochastic dynamic programming for resource allocation and task sequencing among team members. Human constraints were added to the mathematical model to imitate a team member's inability to completely adapt to task requirements. Levis [14] and Coovert et al. [15] have used a Petri net approach to model team performance. The major advantage of using a Petri net approach in team performance analysis is their capability to represent both concurrent and asynchronous team activities. Empirical studies of team performance can be also found in Keller et al. [16], Dyer [17], and Modrick [18].

A primary motivation of mental models is to determine the knowledge (i.e., equipment knowledge, task knowledge, team knowledge, and integration knowledge) and skills required for successful team performance. Mental models are constructs invoked to explain performance differences. Rouse et al. [19] have discussed the role of mental models in team performance in complex systems. They outlined three different functions of mental models: description, explanation, and prediction, and then developed a number of propositions that focus on mental models as mechanisms for forming expectations of team behaviors. They argued that the use of a mental model construct may enable the development of a better understanding of such global team-related phenomena as coordination and communication performance. Rouse $e t$ al. [20] have reviewed and illustrated the algorithmic identification of models of human skills and knowledge. To review a variety of approaches to training and reinforce mental models, see Campbell [21] and Kieras [22].

The methodology developed in this paper is structured, unified, and capable of dealing with the tangible and intangible aspects of forming multi-functional teams. It is based on the Analytical Hierarchy Process (AHP). The AHP methodology is a multicriteria decision-making approach that provides a problem-solving framework and a systematic procedure for representing the elements of any problem. The important advantages of AHP are its simplicity, robustness, and the ability to incorporate "intangibles" into the decision-making process. Also, the user acceptability and confidence in the analysis provided by the AHP methodology is high compared with other multiattribute decision approaches [23].

In this paper, a conceptual framework for prioritizing team members based on customer requirements and product characteristics is presented. The mathematical programming model is developed to determine optimal composition of a team. The application of quality function deployment (QFD) and AHP to select a multifunctional team is discussed in the next section.

\section{The quality function deployment methodology}

The QFD also known as the "House of Quality" was first introduced in 1972 by Akao at Mitsubishi Industries Kobe Shipyard [24]. Since this initial application the "House of Quality" concept has been used worldwide. Hauser and Clausing [24] wrote one of the early papers that introduced the methodology to US manufacturers.

QFD provides a systematic approach to product development and CE. In particular, QFD identifies the general requirements a new product must satisfy, in order to ensure customer preference. The essence of QFD is to translate customer requirements into relevant product design characteristics and thus develop a high quality product. In the "House of Quality" the customer requirements serve as a basic foundation of the process. These requirements are qualitatively related to the engineering domain in the form of a matrix and they identify the relationship between the customer requirements and what engineering must be performed to deliver them. In 
this paper, we use the "House of Quality" to collect and represent the data for the multi-functional team selection model. The application of QFD to the formation of a multi-functional team will now be discussed.

First, project managers, customers, and suppliers develop a QFD planning matrix in which the customer requirements are related to the engineering characteristics (requirements) of the product (see Fig. 1(a)). Then, the engineering requirements are represented by the rows of an engineering characteristics - team members deployment matrix (Fig. 1(b)). In other words, the planning matrix in Fig. 1(b) relates engineering characteristics of the product to the potential team members that are responsible or can provide those characteristics. The matrices in Fig. 1(a and b) are useful in organizing the factors considered in the team selection problem into a hierarchical structure of the AHP.

\section{The analytical hierarchy process approach}

The objective of multicriteria decision making is to select the best available alternative under conflicting criteria. The AHP methodology provides a comprehensive framework for solving such a problem.

The AHP is a multicriteria decision method that uses hierarchical or network structures to represent a decision problem and then develops priorities for the alternatives based on the decision maker's judgments throughout the system [25]. The method developed by Saaty in the 1970s is based on an axiomatic foundation, which has established its mathematical viability [25-28]. The numerous and diverse applications of this technique are due to its simplicity and ability to cope with complex decisionmaking problems. Vargas [29] and Zahedi [30] have provided an extensive list of references on the AHP methodology and its applications. For recent industrial applications of AHP, see Korpela and Tuominen [31], Armacost et al. [32], and Madu and Georgatzas [33].

AHP is based on the following three principles: problem decomposition, comparative judgement, and synthe-

(a)

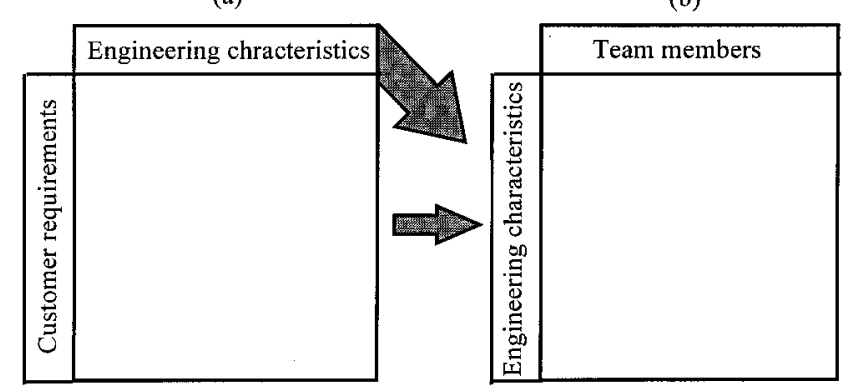

Fig. 1. The basic planning matrices: (a) customer requirements - engineering characteristics planning matrix, (b) engineering characteristics - team members planning matrix. sis of priorities. The AHP begins by decomposing a complex, multicriteria problem into a hierarchy where each level consists of a few manageable elements which are then decomposed into another set of elements. The goal (objective) upon which the best decision should be made is placed at the top level of the hierarchy. The next level of the hierarchy contains attributes or criteria which contribute to the quality of the decisions. Each attribute may be decomposed into more detailed attributes. The lowest level of the hierarchy contains decision alternatives [27].

After the hierarchical network is constructed, one can use comparative judgement to determine the priorities (importance measures) of the attributes at each level of the decision hierarchy, and then synthesize the priorities of attributes to determine the overall priorities of decision alternatives.

First, a comparison matrix which includes Level 1 elements (criteria) of the hierarchy is constructed. Then, a ratio scale pairwise comparison of each pair of criteria with respect to the overall goal is performed. The relative importance of each criterion is estimated using an eigenvector approach [26]. Then, the relative importance of each alternative with respect to each criterion is determined using a similar pairwise comparison. The pairwise comparisons between the criteria as well as between the alternatives are made using the nine-point scale developed by Saaty [27]: 1, 3, 5, 7, and 9 to express the ratio scale preference between the alternatives, 2, 4, 6 , and 8 for compromises, and reciprocals in the inverse comparison. Table 1 summarizes Saaty's relative importance scale modified for the team selection problem. Typically, the decision-maker has to evaluate the upper triangular of the comparison matrix, while reciprocals are placed in the lower triangular. In other words, if scale factor 3 is assigned to entry $(i, j)$ of the matrix, where $i$ and $j$ are the row and column of the comparison matrix, respectively, then a value of $1 / 3$ is assigned to the entry $(j, i)$. Also, when compared with itself each criterion or alternative has equal importance. Therefore, the diagonal elements of the matrix are always equal to one. The advantage of the pairwise comparison of elements instead of direct assignments of preference values is that the latter results in inaccuracies, since the comparison process is more complex. In Section 7, detailed discussion on techniques that enable dramatic reduction in the number of judgements required in a comparison matrix is presented.

The AHP methodology provides an index to measure any inconsistency in judgements in each comparison matrix as well as for the entire hierarchy. A knowledge of inconsistency enables one to determine those judgments that need reassessment. The meaning of consistency in the team selection process is defined as: if a respondent moderately prefers team member $\mathrm{B}$ over $\mathrm{C}$, and team member $\mathrm{C}$ over $\mathrm{D}$, then it is expected that $\mathrm{s} /$ he will prefer 
Table 1. Scale of relative importance (Saaty 1986) modified for team selection

\begin{tabular}{|c|c|c|}
\hline & Definition & Explanation \\
\hline 1 & Equal importance & Two members contribute equally to the goal \\
\hline 3 & Moderate importance of one over another & $\begin{array}{l}\text { Experience and judgment moderately favor one } \\
\text { team member over another }\end{array}$ \\
\hline 5 & Essential or strong importance & Strongly favor one team member over another \\
\hline 7 & Very strong or demonstrated importance & $\begin{array}{l}\text { A team member is very strongly favored } \\
\text { and its dominance is demonstrated in practice }\end{array}$ \\
\hline 9 & Extreme importance & $\begin{array}{l}\text { The evidence of favorite one team member over } \\
\text { another is of the highest possible order of affirmation }\end{array}$ \\
\hline \multirow[t]{2}{*}{$2,4,6,8$} & $\begin{array}{l}\text { Intermediate values between two adjacent } \\
\text { judgments }\end{array}$ & When compromise is needed \\
\hline & Reciprocal & For inverse comparison \\
\hline
\end{tabular}

team member $\mathrm{B}$ over $\mathrm{D}$ is of the highest possible order of affirmation. The consistency index $(C I)$ and consistency ratio $(C R)$ for a comparison matrix $\mathbf{A}$ are computed from (1) and (2), respectively,

$$
\begin{gathered}
C I=\left(\lambda_{\max }-n\right) /(n-1), \\
C R=(C I / A C I) 100 \%,
\end{gathered}
$$

where: $\lambda_{\max }$ is the largest eigenvalue of the comparison matrix, $n$ is the dimension of the matrix, and $A C I$ is the average index for randomly generated weights [26].

If the calculated value of $C R$ for the comparison matrix is less than $10 \%$, the consistency of the pairwise judgment is accepted based on Saaty's rule of thumb [27]. However, when the consistency ratio is greater than $10 \%$, the judgments expressed by the experts are considered inconsistent, and decision-makers are given the opportunity to reconsider their judgments.

The relative preference throughout the hierarchy is obtained from pairwise comparisons of the relative importance of the elements in the same level with respect to the appropriate parent, where a decision-maker or group of decision-makers express their judgments. Aczel and Saaty [34] have demonstrated that collective judgment must satisfy the reciprocal property. This implies that when a group uses the AHP, their judgements can be synthesized into a single judgement according to the geometric mean. For detailed discussion on how to organize group decision making with AHP, including, suggestions for assembling a group, constructing the hierarchy, getting the group to agree, and implementing the results, see Saaty [35], Dyer and Forman [36], and Golden et al. [37]. For the industrial application of AHP in-group decision making, see Islei et al. [38].

In the team selection problem considered in this paper, the AHP is applied as follows. The values that the team members contribute to the criteria established by the customer vary. To select a team, one must elicit all possible characteristics or attributes desired, and then develop a method for assessing their importance to the overall goal. Therefore, all the elements, i.e., customer requirements, engineering characteristics, and team members obtained from the planning matrices in Fig. 1(a and b) form together the model depicted in the hierarchy in Fig. 2. In order to arrive at the team members priorities associated with the engineering characteristics under consideration, one prioritizes all the elements of the hierarchy. After the normalized measure of priority of the team members with respect to each engineering characteristic of Level 2 is obtained, the mathematical programming model (presented next) is used to determine the optimal composition of teams.

\section{The mathematical programming model}

The multi-functional teams formation problem is formulated as an integer programming model. The model is based on the engineering characteristics - team member type priority incidence matrix. Each row of the matrix corresponds to a distinct engineering characteristic of the product. Each column denotes a type of a team member. Each entry $w_{i j}$ in the incidence matrix indicates the priority weight of a team member of type $j$ with respect to engineering characteristic $i$. To formulate the model the following notation is introduced:

$$
\begin{aligned}
& i=\text { index for engineering characteristics; } \\
& j=\text { type of a team member; } \\
& n=\text { number of engineering characteristics; }
\end{aligned}
$$

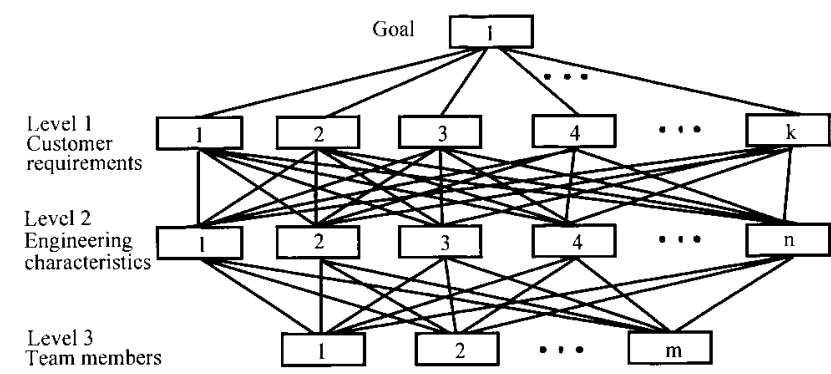

Fig. 2. Hierarchical structure of the team selection problem. 
$m=$ number of types of team members;

$w_{i j}=$ priority weight of team member of type $j$ with respect to engineering characteristic $i$;

$p=$ number of multi-functional teams;

$m_{j}=$ number of projects that a team member of type $j$ can undertake. The value of $m_{j}$ is a function of time, technological, scheduling constraints, etc.;

$x_{i j}=\left\{\begin{array}{l}1 \text { if team member of type } j \text { belongs to the team } \\ \text { that provides engineering characteristic } i \\ 0 \text { otherwise; }\end{array}\right.$

$$
y_{i}=\left\{\begin{array}{l}
1 \text { if team for engineering characteristic } i \text { is } \\
\quad \text { formed, } \\
0 \text { otherwise; }
\end{array}\right.
$$

The objective function of the model $((1)-(6))$ maximizes the total of priority weights of the multi-functional teams.

$$
\begin{gathered}
\max \quad \sum_{i=1}^{n} \sum_{j=1}^{m} w_{i j} x_{i j}, \\
\text { s.t. } \quad \sum_{i=1}^{n} x_{i j} \leq m_{j} \quad j=1, \ldots, m, \\
\sum_{i=1}^{n} y_{i} \leq p, \\
\sum_{j=1}^{m} x_{i j} \leq M y_{i} \quad i=1, \ldots, n, \\
x_{i j}=0,1 \quad i=1, \ldots, n \quad j=1, \ldots, m, \\
y_{i}=0,1 \quad i=1, \ldots, n .
\end{gathered}
$$

Constraint (2) imposes an upper bound on the number of projects that a team member of type $j$ is able to undertake. Constraint (3) specifies the required number of teams. Constraint (4) ensures that a team member of type $j$ belongs to team $i$ only when team $i$ is formed. Constraints (5) and (6) ensure the integrality. The letter $M$ denotes an arbitrary large positive number. Additional constraints, e.g., budget constraint, size of the teams requirement can be easily incorporated into the model ((1)-(6)).

In the next section the AHP framework and mathematical programming formulation are illustrated with an example.

\section{Illustrative example}

Consider an automotive company that intends to form teams to develop a new car. Therefore, a pairwise comparison of the importance of possible team members with respect to the overall goal (development of a car) is required.
Before the AHP is used, planning matrices, discussed in Section 2, are constructed. First, project managers, customers, and suppliers develop a planning matrix in which the customer requirements are related to the engineering characteristics. Then, the desired engineering characteristics are related to the potential team members. The two transformations are shown in Figs. 3 and 4, respectively. Once the matrices shown in Figs. 3 and 4 are developed, the hierarchical structure used in the team selection process is constructed (see Fig. 5). The highest level in the structure is the goal, i.e., build a car. The attributes, i.e., customer requirements and engineering characteristics, which are required to satisfy the goal are placed on Level 1 or 2 , respectively. At the last level of the hierarchy are placed the decision alternatives (i.e., team members).

The next step is to prioritize customer requirements using pairwise comparisons and the relative importance scale listed in Table 1. The judgments of experts in the functional areas of design, manufacturing, production, finance, and marketing are solicited by individual sample surveys. The judgments are collected and synthesized into a single judgment using a geometric mean. A $C R$ is calculated for each comparison matrix to identify the inconsistent judgments that need reassessment. Thus in comparing the 21 customer requirements, the comparison matrix shown in Table 2 is obtained. The resulting priorities of the customer requirements are shown in Fig. 6.

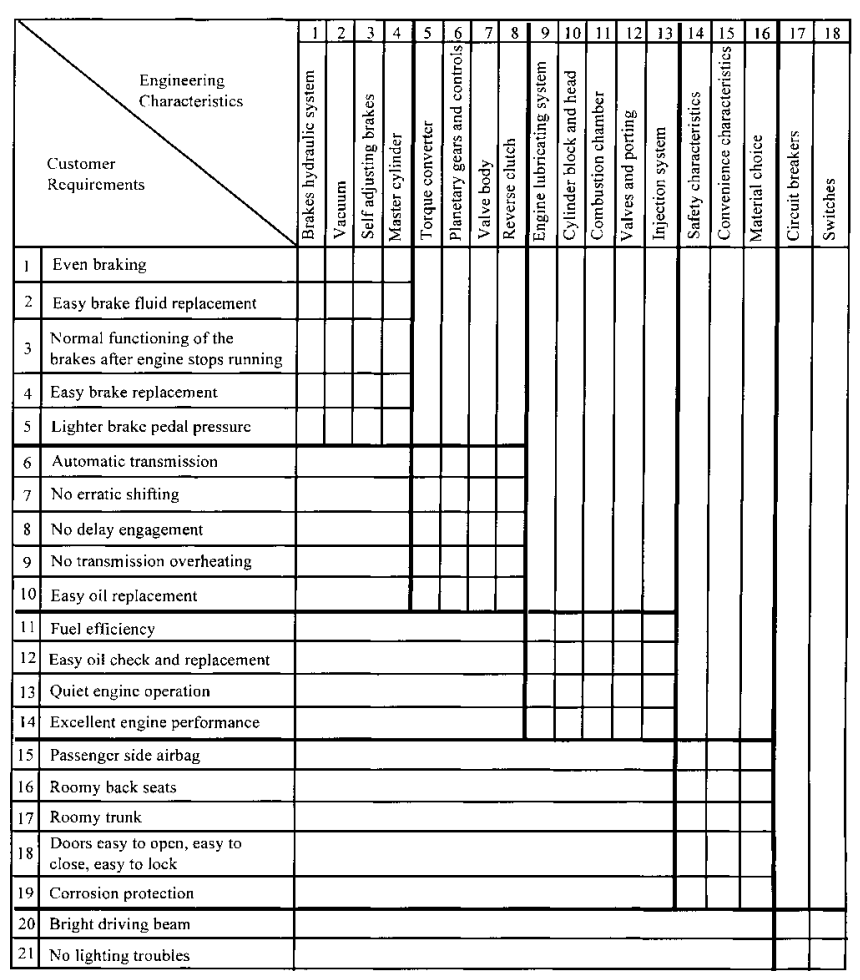

Fig. 3. Customer requirements - engineering characteristics planning matrix. 


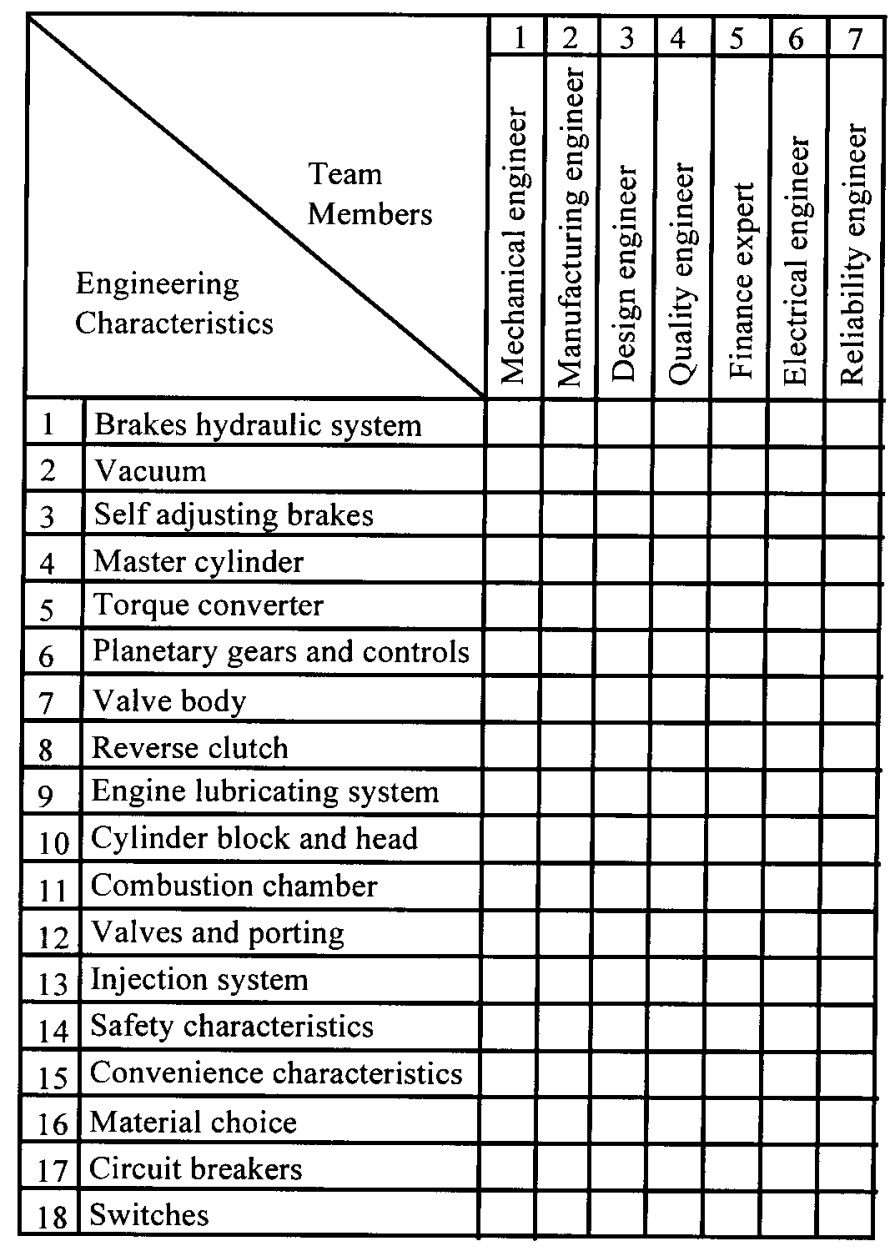

Fig. 4. Engineering characteristics - team members planning matrix.
Table 2 includes the upper triangular of the matrix, as the matrix is reciprocal, i.e., $a_{i j}=1 / \mathrm{a}_{j i}$, where, $a_{i j}$ is entry $(i, j)$ of the matrix. In comparing the fuel efficiency and roomy trunk relative to their importance in the car, a moderate importance for fuel efficiency over roomy trunk is indicated by element $a_{1117}=3$ of the matrix.

The priority vector of the customer requirements is determined using the largest eigenvalue $\lambda_{\max }$ of the matrix in Table 2. The eigenvector corresponding to $\lambda_{\max }$ is the priority vector of the customer requirements. The $C R$ of the matrix in Table 2 is calculated as follows. A computation using the data in Table 2 yields a priority vector $\boldsymbol{w}$ with the largest eigenvalue $\lambda_{\max }=23.6080$. In addition we calculate $C I$ of 0.1304 and a $C R$ of 0.0835 . Note that a value of 1.56 is used for $A C I$ [26].

Next, the second level of the hierarchy, i.e., the engineering characteristics, is prioritized with respect to customer requirements. The engineering characteristics are decomposed since some of them are not pertinent to the customer requirements. For example, for engineering characteristics $5,6,7, \ldots, 18$ the customer requirements 1 , $2,3,4$, and 5 do not need to be elicited. The prioritization is done using comparison matrices that describe the relative impact of the engineering characteristics to the customer requirements. Based on the priorities of the customer requirements, the normalized priorities for the engineering characteristics are derived (see Table 3 and Fig. 7).

Next, a matrix which includes the elements of the lowest level of the hierarchy illustrated in Fig. 5 is constructed. The issue here is to determine which team member has more impact on a considered engineering

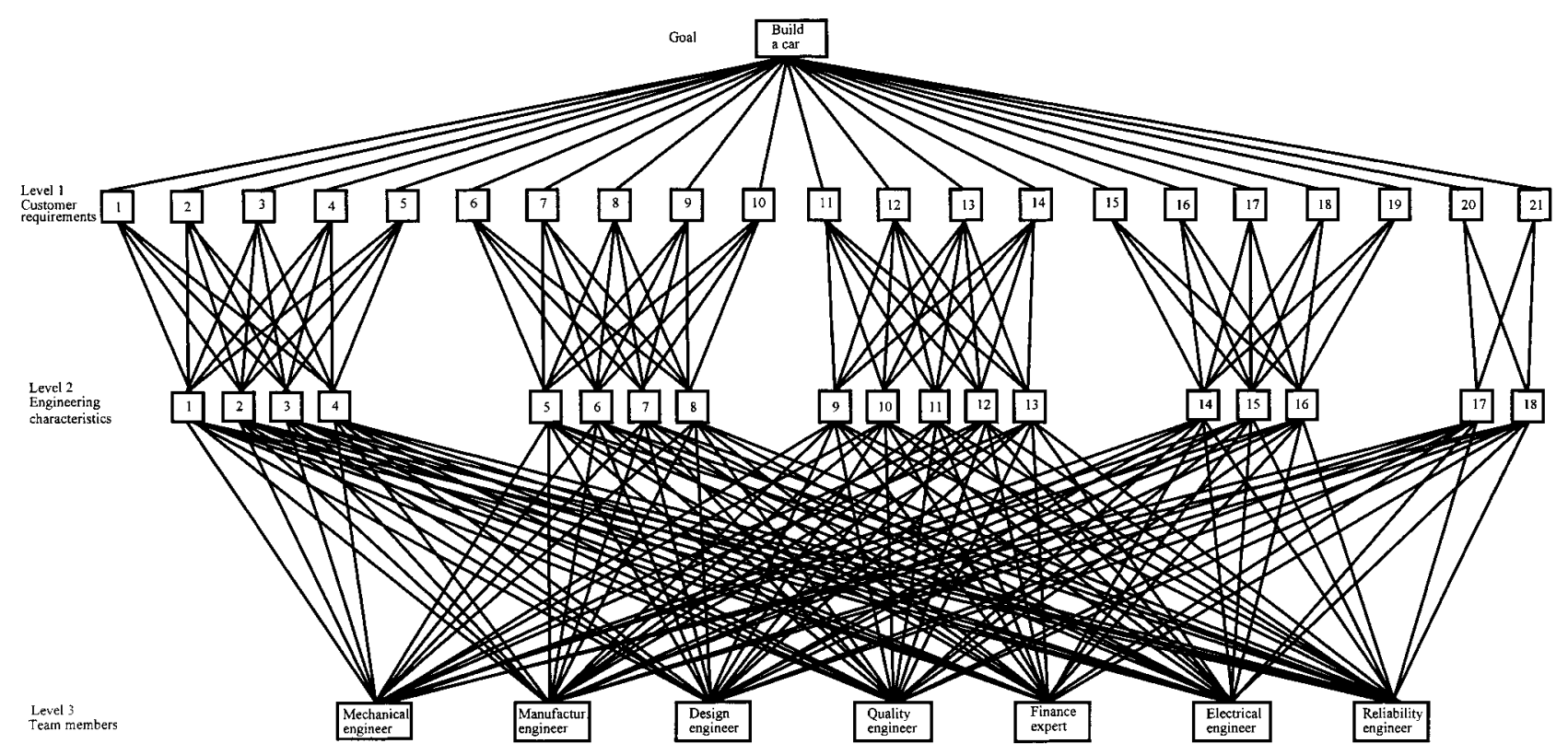

Fig. 5. Hierarchical structure for the team selection problem in Example 1. 
Table 2. Pairwise comparison of customer requirements with respect to the goal

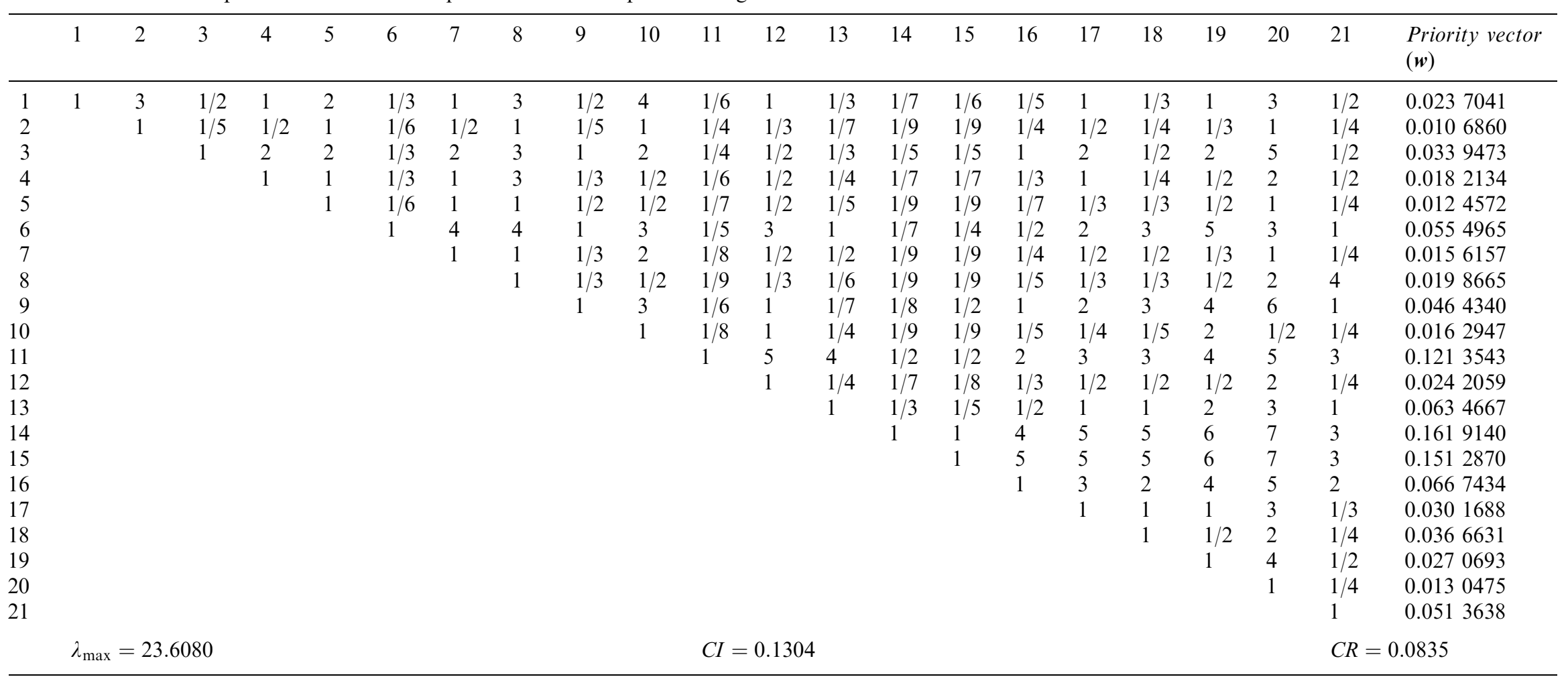




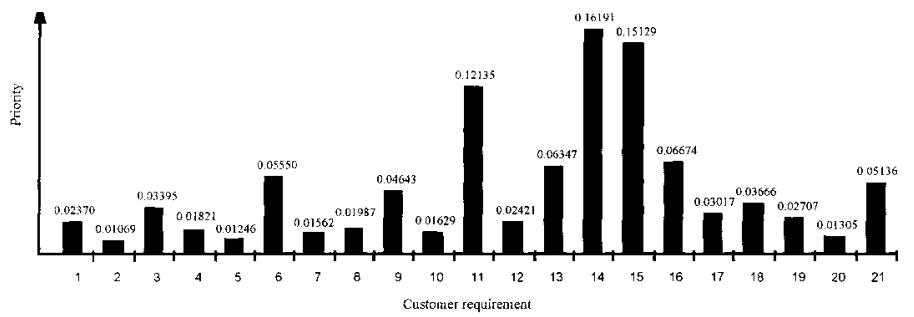

Fig. 6. Priorities of customer requirements.

characteristic. For example, in the first team member comparison matrix one compares the importance of team members in building a hydraulic system for the brakes. Therefore, 18 comparison matrices A1, A2, .., A18 are constructed, one for each engineering characteristic at Level 2. The pairwise comparison of team members with respect to each engineering characteristic in Level 2 is important, as the members receive different ratings when using different criteria.

Following a prioritization scheme similar to the one described above, one derives priorities for each team member with respect to each engineering characteristic at Level 2 . The resulting priority vectors from the 18 matrices are weighted (multiplied) by the importance $\boldsymbol{w}_{i}$ of engineering characteristic $i, i=1, \ldots, 18$, derived in Table 3 . Then, the aggregate priority matrix is constructed which lists the priority measures for each team member with respect to each engineering characteristic of the car, normalized with respect to the overall goal. These priority vectors $\boldsymbol{w}_{1}, \boldsymbol{w}_{2}, \boldsymbol{w}_{3}, \boldsymbol{w}_{4}, \boldsymbol{w}_{5}, \boldsymbol{w}_{6}$, and $\boldsymbol{w}_{7}$ are summarized in Table 4 . The priorities of the team members with respect to each engineering characteristic are summarized in Fig. 8.

Table 3. Normalized priorities of engineering characteristics

\begin{tabular}{rll}
\hline & Engineering characteristic & $\begin{array}{l}\text { Priority } \\
\text { vector }(\boldsymbol{w})\end{array}$ \\
\hline 1 & Brakes hydraulic system & 0.02385 \\
2 & Vacuum & 0.02209 \\
3 & Self adjusting brakes & 0.02416 \\
4 & Master cylinder & 0.02888 \\
5 & Torque converter & 0.05902 \\
6 & Planetary gears and control & 0.03689 \\
7 & Valve body & 0.02644 \\
8 & Reverse clutch & 0.03120 \\
9 & Engine lubricating system & 0.06640 \\
10 & Cylinder block and head & 0.05675 \\
11 & Combustion chamber & 0.07593 \\
12 & Valves and porting & 0.10071 \\
13 & Injection system & 0.07104 \\
14 & Safety characteristics & 0.11573 \\
15 & Convenience characteristics & 0.11791 \\
16 & Material choice & 0.07829 \\
17 & Circuit breakers & 0.02899 \\
18 & Switches & 0.03572 \\
\hline
\end{tabular}

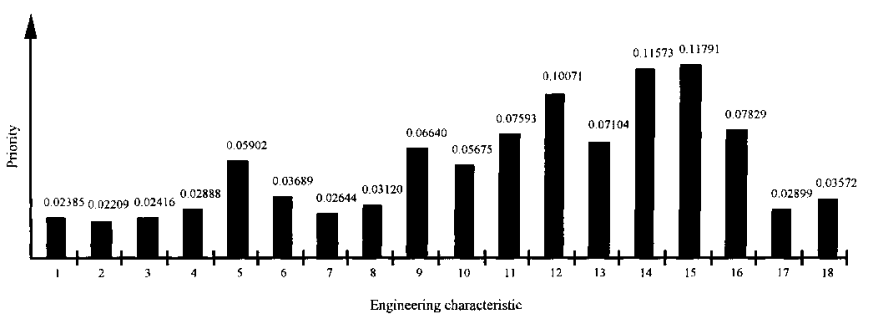

Fig. 7. Normalized priorities of engineering characteristics.

After the matrix in Table 4 is obtained, the mathematical programming model presented in Section 4 determines the optimal composition of teams.

Consider the engineering characteristics - team member type priority incidence matrix in Table 4. Assume a team is required for each engineering characteristic of the car then Table 5 shows the number of potential projects each team member type is able to undertake.

Solving the model $((1)-(6))$ for the incidence matrix in Table 4 and $p=18$, results in the following solution:

$$
\begin{aligned}
& x_{11}=x_{13}=x_{17}=1, x_{12}=x_{14}=x_{15}=x_{16}=0 ; \\
& x_{21}=x_{27}=1, x_{22}=x_{23}=x_{24}=x_{25}=x_{26}=0 ; \\
& x_{31}=x_{32}=x_{33}=x_{37}=1, x_{34}=x_{35}=x_{36}=0 ; \\
& x_{41}=x_{42}=x_{43}=x_{46}=x_{47}=1, x_{44}=x_{45}=0 ; \\
& x_{51}=x_{52}=x_{53}=x_{54}=x_{56}=x_{57}=1, x_{55}=0 ; \\
& x_{61}=x_{62}=x_{63}=x_{64}=x_{66}=x_{67}=1, x_{65}=0 ; \\
& x_{71}=x_{72}=x_{73}=1, x_{74}=x_{75}=x_{76}=x_{77}=0 ; \\
& x_{81}=x_{82}=x_{83}=x_{86}=x_{87}=1, x_{84}=x_{85}=0 ; \\
& x_{91}=x_{92}=x_{93}=x_{94}=x_{96}=x_{97}=1, x_{95}=0 ; \\
& x_{101}=x_{102}=x_{103}=x_{104}=x_{106}=x_{107}=1, x_{105}=0 ; \\
& x_{111}=x_{112}=x_{113}=x_{114}=x_{116}=x_{117}=1, x_{115}=0 ; \\
& x_{121}=x_{122}=x_{123}=x_{124}=x_{125}=x_{126}=x_{127}=1 ; \\
& x_{131}=x_{132}=x_{133}=x_{134}=x_{135}=x_{136}=x_{137}=1 ; \\
& x_{141}=x_{142}=x_{143}=x_{144}=x_{145}=x_{146}=x_{147}=1 ; \\
& x_{151}=x_{152}=x_{153}=x_{154}=x_{155}=x_{156}=x_{157}=1 ; \\
& x_{161}=x_{162}=x_{163}=x_{164}=x_{165}=x_{166}=x_{167}=1 ; \\
& x_{173}=x_{176}=x_{177}=1, x_{171}=x_{172}=x_{174}=x_{175}=0 ; \\
& x_{181}=x_{183}=x_{185}=x_{186}=x_{187}=1, x_{182}=x_{184}=0
\end{aligned}
$$

Based on definition of $x_{i j}$ the following teams are selected:

$\mathrm{T}_{1}=\{\mathrm{ME}, \mathrm{DE}, \mathrm{RE}\}$

$\mathrm{T}_{2}=\{\mathrm{ME}, \mathrm{RE}\}$

$\mathrm{T}_{3}=\{\mathrm{ME}, \mathrm{MF}, \mathrm{DE}, \mathrm{RE}\} ;$

$\mathrm{T}_{4}=\{\mathrm{ME}, \mathrm{MF}, \mathrm{DE}, \mathrm{EE}, \mathrm{RE}\}$,

$\mathrm{T}_{5}=\{\mathrm{ME}, \mathrm{MF}, \mathrm{DE}, \mathrm{QE}, \mathrm{EE}, \mathrm{RE}\}$;

$\mathrm{T}_{6}=\{\mathrm{ME}, \mathrm{MF}, \mathrm{DE}, \mathrm{QE}, \mathrm{EE}, \mathrm{RE}\}$;

$\mathrm{T}_{7}=\{\mathrm{ME}, \mathrm{MF}, \mathrm{DE}\}$

$\mathrm{T}_{8}=\{\mathrm{ME}, \mathrm{MF}, \mathrm{DE}, \mathrm{EE}, \mathrm{RE}\} ;$

$\mathrm{T}_{9}=\{\mathrm{ME}, \mathrm{MF}, \mathrm{DE}, \mathrm{QE}, \mathrm{EE}, \mathrm{RE}\}$;

$\mathrm{T}_{10}=\{\mathrm{ME}, \mathrm{MF}, \mathrm{DE}, \mathrm{QE}, \mathrm{EE}, \mathrm{RE}\}$;

$\mathrm{T}_{11}=\{\mathrm{ME}, \mathrm{MF}, \mathrm{DE}, \mathrm{QE}, \mathrm{EE}, \mathrm{RE}\}$;

$\mathrm{T}_{12}=\{\mathrm{ME}, \mathrm{MF}, \mathrm{DE}, \mathrm{QE}, \mathrm{FE}, \mathrm{EE}, \mathrm{RE}\}$;

$\mathrm{T}_{13}=\{\mathrm{ME}, \mathrm{MF}, \mathrm{DE}, \mathrm{QE}, \mathrm{FE}, \mathrm{EE}, \mathrm{RE}\}$;

$\mathrm{T}_{14}=\{\mathrm{ME}, \mathrm{MF}, \mathrm{DE}, \mathrm{QE}, \mathrm{FE}, \mathrm{EE}, \mathrm{RE}\}$; 
Table 4. Normalized importance measures of each team member with respect to engineering characteristics

\begin{tabular}{|c|c|c|c|c|c|c|c|}
\hline & $M E \boldsymbol{w}_{1}$ & $M F \boldsymbol{w}_{2}$ & $D E \boldsymbol{w}_{3}$ & $Q E \boldsymbol{w}_{4}$ & $F E \boldsymbol{w}_{5}$ & $E E \boldsymbol{w}_{6}$ & $R E \boldsymbol{w}_{7}$ \\
\hline Brakes hydraulic system & 0.00716 & 0.00208 & 0.00117 & 0.00358 & 0.00070 & 0.00164 & 0.00750 \\
\hline Vacuum & 0.00617 & 0.00193 & 0.00108 & 0.00334 & 0.00065 & 0.00188 & 0.00704 \\
\hline Self adjusting brakes & 0.00675 & 0.00211 & 0.00119 & 0.00365 & 0.00071 & 0.00206 & 0.00770 \\
\hline Master cylinder & 0.00816 & 0.00485 & 0.00232 & 0.00312 & 0.00070 & 0.00366 & 0.00606 \\
\hline Torque converter & 0.01592 & 0.00419 & 0.00316 & 0.00762 & 0.00220 & 0.01742 & 0.00851 \\
\hline Planetary gears and controls & 0.01243 & 0.00220 & 0.00220 & 0.00622 & 0.00140 & 0.00622 & 0.00622 \\
\hline Valve body & 0.00183 & 0.00610 & 0.00951 & 0.00356 & 0.00356 & 0.00074 & 0.00114 \\
\hline Reverse clutch & 0.00850 & 0.00281 & 0.00469 & 0.00312 & 0.00081 & 0.00412 & 0.00715 \\
\hline Engine lubricating system & 0.01748 & 0.00809 & 0.00612 & 0.00743 & 0.00299 & 0.00943 & 0.01487 \\
\hline Cylinder block and head & 0.01734 & 0.01109 & 0.01238 & 0.00561 & 0.00142 & 0.00754 & 0.00139 \\
\hline Combustion chamber & 0.01263 & 0.00469 & 0.03822 & 0.00698 & 0.00137 & 0.00889 & 0.00316 \\
\hline Valves and porting & 0.03240 & 0.02249 & 0.01733 & 0.01007 & 0.00423 & 0.01249 & 0.00171 \\
\hline Injection system & 0.01273 & 0.00512 & 0.00255 & 0.00837 & 0.00479 & 0.02206 & 0.01541 \\
\hline Safety characteristics & 0.00964 & 0.00730 & 0.02095 & 0.02307 & 0.01679 & 0.00876 & 0.02921 \\
\hline Convenience characteristics & 0.00491 & 0.02044 & 0.03658 & 0.01306 & 0.01875 & 0.00778 & 0.01639 \\
\hline Material choice & 0.01245 & 0.00924 & 0.01890 & 0.00935 & 0.01681 & 0.00433 & 0.00722 \\
\hline Circuit breakers & 0.00155 & 0.00077 & 0.00693 & 0.00260 & 0.00363 & 0.00831 & 0.00519 \\
\hline Switches & 0.00254 & 0.00146 & 0.00508 & 0.00418 & 0.00585 & 0.01194 & 0.00468 \\
\hline
\end{tabular}

$\mathrm{T}_{15}=\{\mathrm{ME}, \mathrm{MF}, \mathrm{DE}, \mathrm{QE}, \mathrm{FE}, \mathrm{EE}, \mathrm{RE}\}$;

$\mathrm{T}_{16}=\{\mathrm{ME}, \mathrm{MF}, \mathrm{DE}, \mathrm{QE}, \mathrm{FE}, \mathrm{EE}, \mathrm{RE}\}$;

$\mathrm{T}_{17}=\{\mathrm{DE}, \mathrm{EE}, \mathrm{RE}\}$;

$\mathrm{T}_{18}=\{\mathrm{ME}, \mathrm{DE}, \mathrm{FE}, \mathrm{EE}, \mathrm{RE}\}$.
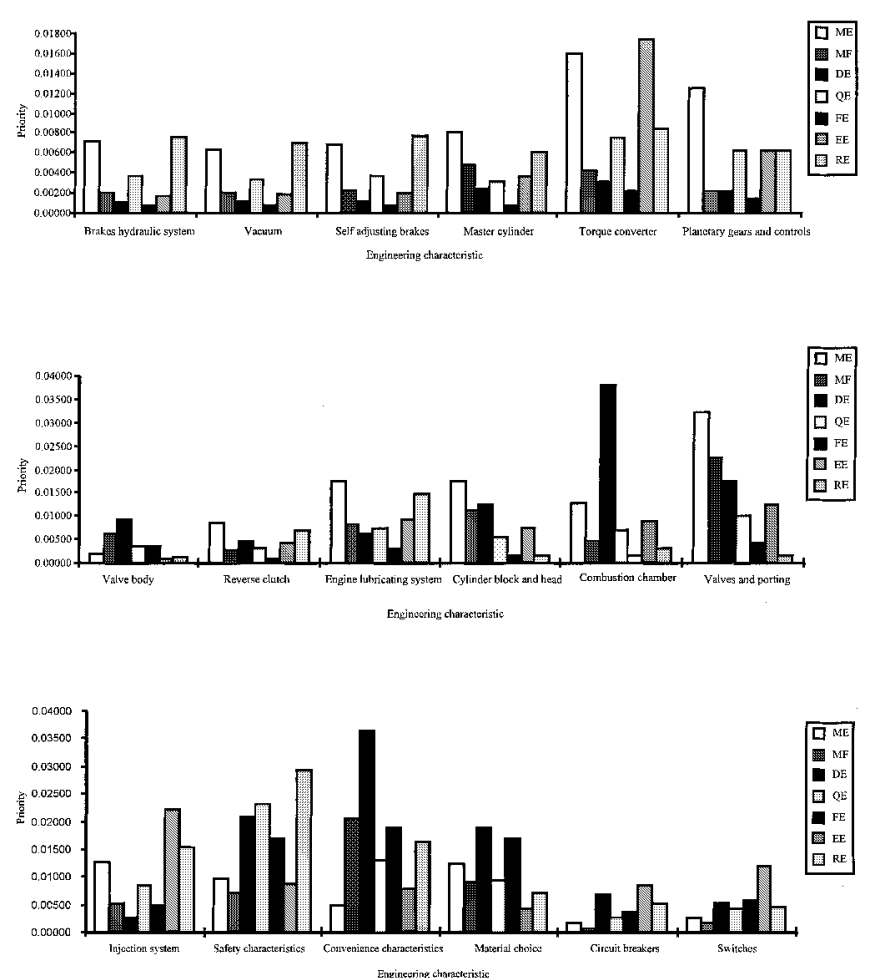

Fig. 8. Normalized priorities of team members with respect to engineering characteristics.

\section{Model extension}

The approach presented in this paper combines the different factors (modules) of the team selection problem into a hierarchical structure. This modularity permits a great degree of flexibility in the formation of teams. For example, the solution of model $((1)-(6))$ provides 18 different teams, one for each engineering characteristic in the hierarchical structure of Fig. 5. To reduce the number of AHP comparison matrices and the size of the model, one can extend the hierarchical structure of Fig. 5 by adding a new level (Level 3), i.e., components (subsystems) of the car, into the hierarchy (see Fig. 9). In this hierarchical structure several engineering characteristics related to a single component (subsystem) of the car. The importance measure of the subsystems of the car can be obtained by summing the importance measures of the engineering characteristics related to the subsystem of the car. Therefore, instead of prioritizing team members with respect to the engineering characteristics of the car, one can prioritize the team members with respect to the components (subsystems) of the car without the need to restructure the entire model. Such a modification reduces the size of the component (subsystem) - team member type priority incidence matrix (see the matrix in Table 6 of size $(5 \times 7)$ compared with the $(18 \times 7)$ matrix in

Table 5. Data for Example 2

\begin{tabular}{clllllll}
\hline & \multicolumn{8}{c}{ Team member type } \\
& $M E$ & $M F$ & $D E$ & $Q E$ & $F E$ & $E E$ & $R E$ \\
\hline $\begin{array}{c}\text { Number of } \\
\text { projects }\end{array}$ & 17 & 14 & 17 & 10 & 6 & 14 & 17 \\
\hline
\end{tabular}




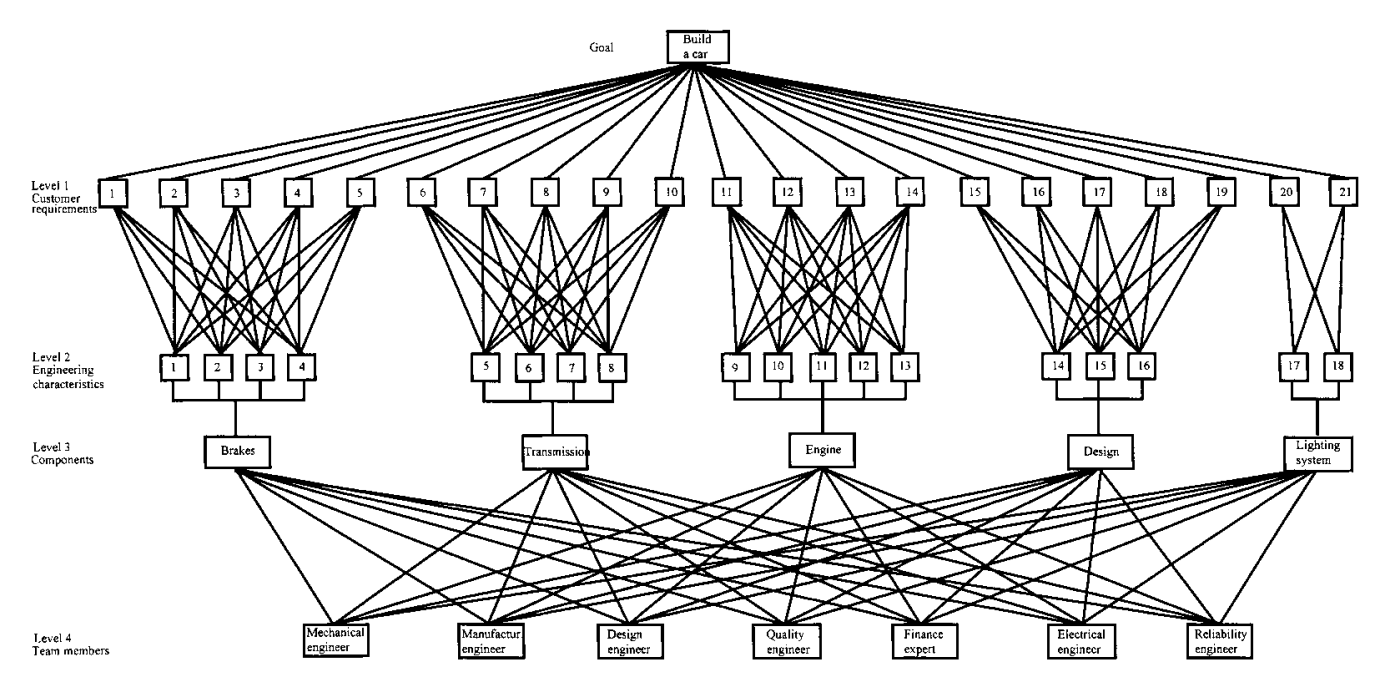

Fig. 9. Extended hierarchical structure for the team selection problem in Example 1.

Table 4). Moreover, the extended model allows one to form a team for each subsystem of the car. For example, if one assumes a team is required for each subsystem of the car and Table 7 shows the number of potential projects each team member type is prepared to undertake, then the model $((1)-(6))$ determines optimal teams for the subsystems of the car.

Solving the model $((1)-(6))$ for the incidence matrix in Table 6 and $p=5$, results in the following solution:

$x_{11}=1, x_{12}=1, x_{13}=1, x_{14}=1, x_{15}=0, x_{16}=1, x_{17}=1$; $x_{21}=1, x_{22}=0, x_{23}=1, x_{24}=0, x_{25}=0, x_{26}=1, x_{27}=1$; $x_{31}=1, x_{32}=1, x_{33}=1, x_{34}=1, x_{35}=1, x_{36}=1, x_{37}=1$; $x_{41}=1, x_{42}=1, x_{43}=1, x_{44}=1, x_{45}=1, x_{46}=1, x_{47}=1$; $x_{51}=0, x_{52}=0, x_{53}=1, x_{54}=0, x_{55}=1, x_{56}=1, x_{57}=0$.

Based on definition of $x_{i j}$ the following teams are selected:

$\mathrm{T}_{\mathrm{b}}=\{\mathrm{ME}, \mathrm{MF}, \mathrm{DE}, \mathrm{QE}, \mathrm{EE}, \mathrm{RE}\} ;$

$\mathrm{T}_{\mathrm{t}}=\{\mathrm{ME}, \mathrm{DE}, \mathrm{EE}, \mathrm{RE}\}$

$\mathrm{T}_{\mathrm{e}}=\{\mathrm{ME}, \mathrm{MF}, \mathrm{DE}, \mathrm{QE}, \mathrm{FE}, \mathrm{EE}, \mathrm{RE}\} ;$

$\mathrm{T}_{\mathrm{d}}=\{\mathrm{ME}, \mathrm{MF}, \mathrm{DE}, \mathrm{QE}, \mathrm{FE}, \mathrm{EE}, \mathrm{RE}\}$

$\mathrm{T}_{1}=\{\mathrm{DE}, \mathrm{FE}, \mathrm{EE}\}$.

\section{Further discussion}

The model presented in this paper provides a framework for team selection in problem solving. The major ad- vantage of this approach is that it can be easily modified and extended to incorporate some other factors, for example, "soft factors", i.e., leadership, morale, group values, personalities of group members, etc., that are important in team formation. The "soft factors" of team selection can be incorporated into the team formation model in many different ways. For example, in the product development problem presented in Section 5, a decision-maker may use the scales of relative importance listed in Table 1 to prioritize the Level 1 and Level 2 elements of the hierarchy of Fig. 5. After the Level 2 elements of the hierarchy are prioritized, $\mathrm{s} /$ he may modify the relative importance scales and their definitions listed in Table 1 to reflect the "soft factors" when selecting (prioritizing) members of a team. Future research will focus on the development and definition of relative importance scales that reflect "soft factors" of team formation. It is believed that the results of numerous empirical studies on team performance that have been presented in the literature will provide a strong information base to help the development of the relative importance scales.

The approach outlined in this paper can also be used to identify the functional representation of a team to provide customer-defined product characteristics. For example the planning matrices presented in Fig. 1(a and b) may be used to relate the engineering characteristics of a product to potential functional areas, i.e., IE, ME, CE,

Table 6. Normalized importance measure of each team member with respect to each subsystem

\begin{tabular}{llllllll}
\hline & $M E \boldsymbol{w}_{1}$ & $M F \boldsymbol{w}_{2}$ & $D E \boldsymbol{w}_{3}$ & $Q E \boldsymbol{w}_{4}$ & $F E \boldsymbol{w}_{5}$ & $E E \boldsymbol{w}_{6}$ & $R E \boldsymbol{w}_{7}$ \\
\hline Power brakes & 0.0413 & 0.0245 & 0.0158 & 0.0120 & 0.0030 & 0.0185 & 0.0300 \\
Transmission & 0.0206 & 0.0081 & 0.0135 & 0.0090 & 0.0020 & 0.0119 & 0.0243 \\
Engine & 0.0804 & 0.0514 & 0.0574 & 0.0260 & 0.0066 & 0.0254 & 0.0574 \\
Design & 0.0168 & 0.0727 & 0.1302 & 0.0466 & 0.0668 & 0.0277 & 0.0584 \\
Lighting system & 0.0024 & 0.0014 & 0.0011 & 0.0043 & 0.0060 & 0.0138 & 0.0086 \\
\hline
\end{tabular}


Table 7. Data for the extended model

\begin{tabular}{llllllll}
\hline & \multicolumn{8}{c}{ Team member type } \\
& $M E$ & $M F$ & $D E$ & $Q E$ & $F E$ & $E E$ & $R E$ \\
\hline $\begin{array}{c}\text { Number of } \\
\text { projects }\end{array}$ & 4 & 3 & 5 & 3 & 3 & 5 & 4 \\
\hline
\end{tabular}

EE, Finance, Marketing, that are important in providing customer characteristics. The relative scales of Table 1 can be used to prioritize functions with respect to the engineering characteristics. The linear programming model presented in Section 4 can be used to identify a functional representation of a team. Once a functional representation of a team is identified, one may select team members based on "soft factors", i.e., leadership, morale, etc.

The AHP approach used in this paper provides several important advantages for team formation. AHP provides an index for measuring inconsistency for each matrix of comparisons and for the entire team formation hierarchy. It allows us to identify where the most inconsistent judgements are and to change them if desired to improve consistency. Furthermore, the application of AHP to group decision-making have proven to be efficient. The major advantages of AHP in group decision-making, as compared to other multi-criteria methods, are the ease of use and the ability to handle inconsistencies in judgments. The AHP does not require an individual or a group to be perfectly consistent when making pairwise comparisons. Numerous applications support Saaty's claim that individuals and groups easily adapt to a pairwise comparison mechanism and find it easy to use. Moreover, several questioning (comparison) techniques have been developed that guide the user through the comparison procedure and dramatically reduce the number of judgments a decision-maker is required to make in AHP.

One of the major concerns about the use of the AHP approach in the team selection model is the amount of effort required to complete pairwise comparisons in large hierarchies. The eigenvalue approach used in the AHP approach requires $n(n-1) / 2$ comparisons to establish the priorities of $n$ elements. When $n$ is large the pairwise comparison process may be computationally intensive. The incomplete pairwise comparison (IPC) and global stopping rule (GSR) techniques developed by Harker $[39,40]$ and Millet and Harker [41], respectively, allow one to dramatically reduce the number of pairwise comparisons made in an AHP session. Harker $[39,40]$ has shown that when a comparison matrix $\mathbf{A}$ is consistent, which means that a decision-maker makes perfectly consistent judgements, only $(n-1)$ comparisons are needed to obtain the top row of matrix A. All other matrix entries can be derived from the relation $a_{i j}=a_{i 1} a_{1 j}$ [42]. Although a minimum of $(n-1)$ judgements are required to establish the ratios between $n$ elements, AHP uses $n(n-1) / 2$ comparisons. Thus, the eigenvector approach used in AHP includes a great deal of redundancy. This redundancy diminishes the impact of inconsistent judgments on the final attribute weight. Harker $[39,40]$ developed the IPC technique which reduces the pairwise comparison effort by arranging the questions (comparisons) in decreasing information value and by stopping the comparison process when the added value of questions decreases below a certain level. The IPC technique uses the gradient of the right and left Perron vectors to calculate the attribute weights $w$ [39]. The technique leads the decisionmaker to the next comparison that has the greatest impact on the attribute weights, i.e., the comparison with the largest absolute gradient of the right Perron vector. The questioning (pairwise comparison) is terminated when the maximum absolute difference in the attribute weights from one question to the next is less than certain specified number. The stopping rule makes sure that further questioning will not alter the attribute weights. The IPC approach provides a 30 to $40 \%$ saving in the number of comparisons required in AHP. Millet and Harker [41] have developed the GSR technique that provides opportunities for a further reduction in the required number of comparisons in AHP through a globally effective elicitation process. The GSR is a top-bottom approach in which the decision-maker first explores the upper nodes of the hierarchy before prioritizing the lower ones. The technique is based on the following three concepts: (1) use the current node global weight to determine the effort allocation process; (2) freeze the node that has a relatively low, compared with its peers, global weight; and (3) cease elicitation of ratios for clearly inferior alternatives. Based on the above concepts Millet and Harker [41] developed globally effective allocation of questions that allows an impressive 60 to $70 \%$ saving in the number of judgements for large hierarchies. The GSR approach even allows one to reduce the minimum number of comparisons per node to below $(n-1)$. This is achieved by suspending elicitation for branches with negligible weight compared to their peers. The IPC and GSR techniques speed up the elicitation process and provide more flexibility in the pairwise ranking session by allowing a decision-maker to avoid making a direct comparison between two alternatives when s/he is unwilling or unsure about the judgment.

Several companies, e.g., General Motors (GM), Ford, are using AHP to support decision-making in manufacturing and product development. For example, GM uses AHP to prioritize customer requirements and engineering characteristics in product development. For such companies the Level 1 and Level 2 elements of the team formation hierarchy have already been prioritized. Therefore, to determine the composition of teams with a linear programming approach one only needs to obtain the priorities of team members with respect to the engineering characteristics. This further reduces the 
number of comparisons required in AHP for the team selection model and makes the approach more attractive to industry. Furthermore, over the life cycle of a new product hundreds of teams may be formed. It is important to emphasize that the Level 1 and Level 2 elements of the team formation hierarchy have to be prioritized only once, i.e., at the beginning of a new product development, while the teams are formed and broken continuously throughout the entire product development phase. The approach presented in this paper can be successfully used at the early stages of product development to identify the functional representation of teams under various constraints, i.e., time, budget, size of the teams, etc. Furthermore, for similar products, e.g., for various car models, certain information from old comparisons (judgements) may be used. For example, when a new car model that includes additional customer requirements is under consideration, then one can add additional factors reflecting these new requirements into the team selection hierarchy developed for the old model of the car and perform the analysis without restructuring the entire model. Similarly, factors can be removed when necessary.

\section{Conclusion}

A conceptual framework was presented for the selection of multi-functional teams. A QFD planning matrix was used to collect and represent data in a multi-functional team selection model. The AHP was applied in order to prioritize team members based on customer requirements and engineering characteristics of the product. A mathematical programming model was formulated to determine the required team compositions. The approach presented in this paper combined the different factors (modules) of the team selection problem into a hierarchical structure of the AHP. This modularity permits a large degree of flexibility in the formation of teams, i.e., one can add an additional factor to the team selection hierarchy and perform the analysis without restructuring the entire model. Similarly, the factors can be removed when necessary. A detailed discussion on possible modifications and extensions of the model to include "soft factors" in team selection was presented. The techniques and global questioning strategy that allow impressive savings in the number of judgements in AHP were reviewed. The approach presented in this paper is perhaps the first attempt to formalize the team selection process. The methodology discussed in the paper can be applied to numerous areas of team formation, including concurrent engineering. Future research will concentrate on the development and definition of relative importance scales reflecting "soft factors", i.e., leadership, group performance, morale, etc., in team selection. It is believed that the results of numerous empirical studies on team performance presented in the literature will provide a strong data base for the development of these relative importance scales.

\section{References}

[1] Clark, K.B., Chew, W.B. and Fujimoto, T. (1992) Product development process. Technical Report, Harvard Business School, Boston.

[2] Carter, D.E. and Baker, B.S. (1992) Concurrent Engineering: The Product Development Environment for the 1990s, Addison-Wesley, Reading, MA.

[3] Salas, E., Dickinson, T.L., Converse, S.A. and Tannenbaum, S.I. (1992) Toward an understanding of team performance and training, in Team: Their Training and Performance, Swezey, W. and Salas, E. (eds), Norwood, Ablex, NJ.

[4] Belson, D. (1994) Concurrent engineering, in Handbook of Design, Manufacturing, and Automation, Dorf, R.D. and Kusiak, A. (eds), John Wiley \& Sons, New York, pp. 25-33.

[5] Lawrence, P. and Lorsch (1967) Organization and Environment: Managing Differentiation and Integration. Boston, Harvard Business School.

[6] Askin, R.G. and Sodhi, M. (1994) Organization of teams in concurrent engineering, in Handbook of Design, Manufacturing, and Automation, Dorf, R.D. and Kusiak, A. (eds), John Wiley \& Sons, New York, NY, pp. 85-105.

[7] Reddy, Y.V., Srinivas, K., Jagannathan, V. and Karinthi, R. (1993) Computer support for concurrent engineering. Computer, 1 (1), 12-16.

[8] Klein, M. (1993) Capturing design rationale in concurrent engineering teams. Computer, January, 39-47.

[9] Levine, J.M. and Moreland, R.L. (1990) Progress in small group research, in Annual Review Psychology, Vol. 41, Rosenzweig, M.R. and Porter, L.W. (eds), pp. 585-634.

[10] Armstrong, Jr., J.B. (1990) Distributed decision making for command and control of complex dynamic systems. Technical Report CHMSR-90-1, Georgia Institute of Technology, Atlanta, GA.

[11] Hauptman, O. and Hirji, K.K. (1996) The influence of process concurrency on project outcomes in product development: an empirical study of cross-functional teams. IEEE Transactions on Engineering Management, 43 (2), 153-164.

[12] Kleinman, D.L., Luh, P.B., Pattipati, K.R. and Serfati, D. (1992), Mathematical models of team distributed decision making, in Team: Their Training and Performance, Swezey, W. and Salas, E. (eds), Norwood, Ablex, NJ.

[13] Luh, P.B., Pattipati, K.R. and Kleinman, D.L. (1990) Task and resource coordination in human teams, in Proceedings $5^{\text {th }}$ International Symposium on Intelligent Control, Computer Society Press, Washington, D.C., pp. 116-120.

[14] Levis, A.H. (1988) Human organizations as distributed intelligence systems, in Proceedings IFAC/IMACS International Symposium on Distributed Intelligent Systems, Springer, New York.

[15] Coovert, M.D., Salas, E. and Craiger, J.P. (1990) Understanding team performance measures: application of Petri nets, in Proceedings 1990 IEEE International Conference on Systems, Man, and Cybernetics, IEEE, New York, pp. 214-217.

[16] Keller, R.T., Julian, S.D. and Kedia, B.L. (1996) A multinational study of work climate, job satisfaction, and productivity of R\&D teams. IEEE Transactions on Engineering Management, 42 (1), 48 55.

[17] Dyer, J.C. (1984) Team research and team training: state-of-theart review, in Human Factors Review, Muckler, F. A. (ed), Human Factors Society. Santa Monica, CA, pp. 285-323.

[18] Modrick, J.A. (1986) Team performance and training, in Human Productivity Enhancement: Training and Human Factors in Systems Design, Vol. 1, Zeidner, J. (ed), Praeger, New York, NY. pp. $130-166$. 
[19] Rouse, W.B., Cannon-Bowers, J.A. and Salas, E. (1992) The role of mental models in team performance in complex models. IEEE Transactions on Systems, Man, and Cybernetics, 22 (6), 1296-1308.

[20] Rouse, W.B., Hammer, J.M. and Lewis, C.M. (1989) On capturing human skills and knowledge: algorithmic approaches to model identification. IEEE Transactions on Systems, Man and Cybernetics, 19 (3), 558-572.

[21] Campbell, G. (1990) The theory and training of mental models. Technical Report Naval Training and Systems Center, Orlando, FL.

[22] Kieras, D.E. (1988) What mental models should be taught: choosing instructional content for complex engineered systems. in Intelligent Tutoring Systems: Lessons Learned, Psotka, J., Massey, L.D. and Mutter, S.A. (eds), Erlbaum, NJ, pp. 85-111.

[23] Shoemaker, P.J. and Ward, C.C. (1982) An experimental comparison of different approaches to determining weights in additivity utility models. Management Science, 28 (2), 128-196.

[24] Hauser, J.R. and Clausing, D. (1988) The house of quality. Harvard Business Review, May-June, 63-73.

[25] Saaty, T.L. (1987) Concepts, theory, and techniques: rank generation, preservation, and reversal in the analytical hierarchy process. Decision Sciences, 18, 157-177.

[26] Saaty, T.L. (1981) The Analytical Hierarchy Process, McGraw Hill, New York, NY.

[27] Saaty, T.L. (1986) Axiomatic foundation of the analytical hierarchy process. Management Science, 32 (7), 841-855.

[28] Harker, P.T. and Vargas, L.G. (1987) Theory of ratio scale estimation: Saaty's analytical hierarchy process. Management Science, 33 (11), 1383-1403.

[29] Vargas, L.G. (1990) An overview of the analytical hierarchy process and its applications. European Journal of Operational Research, 48 (1), 2-8.

[30] Zahedi, F. (1986) The analytical hierarchy process - a survey of the method and its applications. Interfaces, 16 (4), 96-108.

[31] Korpela, J. and Tuominen, M. (1996) Benchmarking logistics performance with an application of the analytical hierarchy process. IEEE Transactions on Engineering Management, 43 (3), 323 333.

[32] Armacost, R.L., Componation, P.J., Mullens, M.A. and Swart, W.W. (1994) An AHP framework for prioritizing customer requirements in QFD: an industrial housing application. IIE Transactions, 26 (4), 72-79.

[33] Madu, C.N. and Georgatzas, N.C. (1991) Strategic thrust of manufacturing automation decision: a conceptual framework. IIE Transactions, 23 (2), 138-147.

[34] Aczel, J. and Saaty, T.L. (1983) Procedures for synthesizing ratio judgments. Journal of Mathematical Psychology, 27 (1), 93-102.

[35] Saaty, T.L. (1982) Decision Making for Leaders, Lifetime Learning, New York, NY.
[36] Dyer, R.F. and Forman, E.H. (1992) Group decision support with the analytical hierarchy process. Decision Support Systems, 8,99 124.

[37] Golden, B.L., Wasil, E.A. and Harker, P.T. (1989) The Analytical Hierarchy Process: Applications and Studies, Springer-Verlag, New York.

[38] Islei, G., Lockett, G., Cox, B. and Stratford, M. (1991) A decision support system using judgmental modeling: A case of R\&D in the pharmaceutical industry. IEEE Transactions on Engineering Management, 38, 202-209.

[39] Harker, P.T. (1987) Alternative modes of questioning in the analytical hierarchy process. Mathematical Modelling, 9 (3-5), 353360 .

[40] Harker, P.T. (1987) Incomplete pairwise comparisons in the analytical hierarchy process. Mathematical Modelling, 9 (11), 837-848.

[41] Millet, I. and Harker, P.T. (1990) Globally effective questioning in the analytical hierarchy process. European Journal of Operational Research, 48 (1), 88-97.

[42] Saaty, T.L. and Vargas, L.G. (1984) Inconsistency and rank preservation. Journal of Mathematical Psychology, 28, 205-214.

\section{Biographies}

Dr. Armen Zakarian received a B.S. in Mechanical Engineering from Yerevan Polytechnic University, Yerevan, Armenia, a M.S. in Industrial and Systems Engineering from the University of Southern California, Los Angeles, California, and a Ph.D. in Industrial Engineering from the University of Iowa, Iowa City, Iowa, in 1997. He is an Assistant Professor in Industrial and Manufacturing Systems Engineering in the University of Michigan-Dearborn. He taught at both undergraduate and graduate levels at the University of Iowa and has held a visiting faculty position at the American University of Armenia. His research interests include reengineering of manufacturing, product development and business processes, reliability and risk analysis of process models, and modeling and analysis of manufacturing systems.

Dr. Andrew Kusiak is Professor of Industrial Engineering at the University of Iowa, Iowa City, Iowa. He is interested in product development, manufacturing, healthcare informatics and technology, and applications of artificial intelligence and optimization. He has published research papers in journals sponsored by AAAI, ASME, IEEE, IIE, INFORMS, ESOR, IFIP, IFAC, IPE, ISPE, and SME. Dr. Kusiak speaks frequently at international meetings, conducts professional seminars, and consults for industrial corporations. He serves on the editorial boards of sixteen journals, edits book series, and is the Editorin-Chief of the Journal of Intelligent Manufacturing. 